\title{
Evaluation of Children with Congenital Heart Disease Hospitalized with the Diagnosis of Lower Respiratory Tract Infection
}

\author{
(D) Yasemin Özdemir Şahan1, (1) Erhan Kılıçoğlu2, (1) Zülal Ülger Tutar1 \\ ${ }^{1}$ Ege University Faculty of Medicine, Department of Pediatric Cardiology, Izmir, Turkey \\ 2Ege University Faculty of Medicine, Department of Pediatrics, Izmir, Turkey
}

\begin{abstract}
Aim: Lower respiratory tract infections are an important reason for mortality and morbidity in children with congenital heart disease. This study aimed to evaluate 50 children who had congenital heart disease and were hospitalized with lower respiratory tract infection in the Ege University Faculty of Medicine Pediatrics Hospital.

Materials and Methods: Fifty pediatric patients were taken into the study. Their clinical symptoms, acute phase reactants, chest X-rays, bacterial culture of transtracheal aspirate, respiratory virus panel (with multiplex polimerase chain reaction) from nasopharyngeal swab were examined. The groups were evaluated in terms of age, gender, enviromental smoke exposure, living with school-aged siblings, Respiratory Syncytial virus (RSV) prophylaxis, hospitalization time, causative pathogen, additional risk factors. Results: Of the 50 cases, $12(24 \%)$ were cyanotic, $38(76 \%)$ were acyanotic. There were 26 boys and 24 girls. The most common diagnosis in the acyanotic group was hemodynamically significant VSD (isolated or with other diagnoses) with 20 cases. The average age of the cyanotic group was $23.88 \pm 28.81$, and the acyanotic group was $12.25 \pm 15.45$ months old. Hospitalizations most frequently occured in winter. The most frequent viral agent was RSV, which was not seen in the cyanotic group. All of the RSV infected patients were under 12 months old. In $16.7 \%$ of cyanotic and $52.6 \%$ of acyanotic patients there were extra risk factors such as immune deficiency, Down syndrome, prematurity, Di George syndrome, cerebral palsy, postoperative early period. Three cases lost their lives due to severe respiratory failure. There was no statistically significant difference between the two groups when compared for demografic variables, risk factors, causative pathogens, hospitalization times.

Conclusion: Lower respiratory tract infections and especifically RSV pneumonia are important causes of mortality and morbidity in patients diagnosed with congenital heart disease. To prevent risk factors, more studies must be done.

Keywords: Respiratory, infections, congenital, heart, disease
\end{abstract}

\section{Introduction}

The incidence of congenital heart disease (CHD) in the general population is about $1 \%$ and varies from $4 / 1000$ to 50/1000 live births (1). Children with CHD have many complications concerning all of the organ systems, the respiratory system being the most important. Lower respiratory tract infection (LRTI) is a serious mortality and morbidity reason for children with CHD. Hemodynamically significant-CHD (HS-CHD) with pulmonary congestion poses a higher risk for LRTI and hospitalizations. Respiratory Syncytial virus (RSV) pneumonia is commonly seen in the first two years of life (2). Socio-economic and environmental risk factors such as prematurity, male sex, living with school-aged siblings, exposure to environmental smoking may increase susceptibility to RSV disease and frequent hospitalizations $(3,4)$. In this study, 50 children with $\mathrm{CHD}$, who were hospitalized with the diagnosis of LRTI, were analyzed in the Ege University Faculty of Medicine Pediatrics Hospital.

\section{Address for Correspondence}

Yasemin Özdemir Şahan MD, Ege University Faculty of Medicine, Department of Pediatric Cardiology, Izmir, Turkey

Phone: +90 5062915824 E-mail: dr.yaseminozdemir@gmail.com ORCID ID: orcid.org/0000-0003-4219-9532

Received: 16.08.2017 Accepted: 01.12.2017

Presentation at a meeting: Poster presentation at the $7^{\text {th }}$ World Congress of Pediatric Cardiology and Cardiac Surgery, 16-21 July 2017 , Barcelona

${ }^{\circ}$ Copyright 2018 by Ege University Faculty of Medicine, Department of Pediatrics and Ege Children's Foundation

The Journal of Pediatric Research, published by Galenos Publishing House. 


\section{Materials and Methods}

Fifty pediatric CHD patients, aged from 1 to 108 months, hospitalized with LRTI between December 2013 and 2015 were included in our study. Ege University Faculty of Medicine Ethics Commitee approved the study (approval number: 14-11/11). After being informed of the purpose and content of the study by the doctor and having read the information for patients, all the parents gave written informed consent. Exclusion criteria was refusal of parental consent to participate in the study. The eligible patients were evaluated prospectively. For these patients who were previously diagnosed or had recently been diagnosed with $\mathrm{CHD}$, acute phase reactants, postero-anterior chest X-rays, bacterial culture of transtracheal aspirate, respiratory virus panel (with multiplex polimerase chain reaction) from nasopharyngeal swab were examined. Demographic and clinical data were collected from the parents. The patients were classified into two groups as cyanotic and acyanotic. The groups were examined in terms of age, gender, demographic features, additional risk factors, exposure to smoke, living with schoolaged siblings, having received palivizumab prophylaxis dose, hospitalization time, causative pathogen and complications.

\section{Statistical Analysis}

All continuous variables were analyzed using standard descriptive statistics with mean \pm standard deviation values. As qualitative variables, median, minimum and maximum values were expressed. For non-normal distribution of independent measures, Mann Whitney $U$ test was applied to the number of categories falling into two and Kruskal Wallis $\mathrm{H}$ test was applied to the number of categories falling into three or more. The data sets in categorical structures were analysed with chi-square (Yates\&Fisher). Statistical significance was defined as $p<0.05$. All data analysis is was done with SPSS v21.0 (IBM Corporation, Armonk, New York, USA) software.

\section{Results}

Of the 50 cases, 12 (24\%) were diagnosed with cyanotic and 38 (76\%) with acyanotic CHD. Boy/girl ratio was 26/24. In the acyanotic group, 6 cases (12\% of 50 patients) were diagnosed with venticular septal defect (VSD) and atrial septal defect (ASD); 6 cases (12\%) with only VSD, 4 cases $(8 \%)$ with only ASD; 4 cases (8\%) with patent ductus arteriosus (PDA), 4 cases (8\%) with endocardial cushion defect, 1 case (2\%) with PDA+ASD, 1 case (2\%) with aortic coarctation (AC), 2 cases (4\%) with double outlet right ventricle (DORV) repair, 1 case (2\%) with repair of tricuspit atresia (TA) with Fontan procedure, and 1 case $(2 \%)$ with repair of d-transposition of great arteries with Jatenne procedure. All the other cases had mixed type of diagnostics including VSD. In the cyanotic group, 4 cases (8\%) were diagnosed with Tetralogy of Fallot (TOF), 4 cases (8\%) with DORV, 2 cases (4\%) with truncus arteriosus, 1 case $(2 \%)$ with pulmonary atresia, 1 case $(2 \%)$ with TA. The average age of the patients diagnosed with cyanotic CHD was $23.88 \pm 28.81$ months, and that of the acyanotic CHD patients was $12.25 \pm 15.45$ months. Six $(50 \%)$ of the cyanotic and $28(73.7 \%)$ of the acyanotic patients were infants. Seven $(58.3 \%)$ of the cyanotic and $27(71.1 \%)$ of the acyanotic patients were living with 2 or more school-aged siblings. Five $(41.7 \%)$ of the cyanotic and 12 (31.6\%) of the acyanotic patients had been exposed to environmental smoke (Table I). There was no statistically significant difference between the groups when compared for demografic variables, passive smoking, LRTI with viral or bacterial agent, and hospitalization time. Twenty-six of 38 acyanotic patients (68.4\%) had HS-CHD before 2 years of age, and 18 of 26 (69.2\%) patients received palivizumab prophylaxis dose because the other 8 patients' hospitalization was a long time away from the RSV season. In the acyanotic group, the average dose of palivizumab received was $2.30 \pm 2.04$. Of the 12 cyanotic patients $(66.6 \%), 8$ received palivizumab prophylaxis at an avarage dose of $2.44 \pm 1.68$. Four of them could not receive the prophylaxis because of same reason as the 8 patients in the acyanotic group. Two of the cyanotic (16.7\%) and 20 of the acyanotic patients (52.6\%) had extra risk factors such as immune deficiency, Down syndrome, prematurity, Di George syndrome, cerebral palsy, postoperative early

\begin{tabular}{|c|c|c|c|}
\hline & $\begin{array}{l}\text { Cyanotic } \\
n=12(\%)\end{array}$ & $\begin{array}{l}\text { Acyanotic } \\
n=38(\%)\end{array}$ & \begin{tabular}{|l}
$p$ \\
value
\end{tabular} \\
\hline \multicolumn{3}{|l|}{ Sex } & \multirow{3}{*}{0.958} \\
\hline Female & $6(50)$ & $17(44.7)$ & \\
\hline Male & $6(50)$ & $21(55.3)$ & \\
\hline \multicolumn{3}{|l|}{ Age } & \multirow{3}{*}{0.163} \\
\hline$<12$ months & $6(50)$ & $28(73.7)$ & \\
\hline$\geq 12$ months & $6(50)$ & $10(26.3)$ & \\
\hline \multicolumn{3}{|c|}{ School-aged siblings } & \multirow{3}{*}{0.438} \\
\hline 1 & $5(41.7)$ & $11(28.9)$ & \\
\hline 2 or more & $7(58.3)$ & $27(71.1)$ & \\
\hline \multicolumn{3}{|c|}{ Exposure to smoke } & \multirow{3}{*}{0.728} \\
\hline Yes & $5(41.7)$ & $12(31.6)$ & \\
\hline No & $7(58.3)$ & $26(68.4)$ & \\
\hline \multicolumn{3}{|c|}{ Causative viral agent } & \multirow{3}{*}{1.000} \\
\hline Yes & $2(16.7)$ & $7(18.4)$ & \\
\hline No & $10(83.3)$ & $31(81.6)$ & \\
\hline \multicolumn{3}{|c|}{ Causative bacterial agent } & \multirow{3}{*}{1.000} \\
\hline Yes & $1(8.3)$ & $4(10.5)$ & \\
\hline No & $11(91.7)$ & $34(89.5)$ & \\
\hline \multicolumn{3}{|c|}{ PICU admission } & \multirow{3}{*}{0.076} \\
\hline Yes & $1(8.3)$ & $13(34.2)$ & \\
\hline No & $11(91.7)$ & $25(65.8)$ & \\
\hline
\end{tabular}

PICU: Pediatric intensive care unit 
period. Hospitalizations most frequently occured in winter (17 cases, 34\%), and secondly in spring (14 cases, 28\%). Viral agents were detected on the nasopharyngeal swab of 2 cyanotic patients (16.7\%) and 7 acyanotic patients (18.4\%). RSV was the most frequent viral agent which was isolated in totally 5 patients diagnosed with PDA, VSD+ASD, operated DORV and isolated VSD, (2 patients had viral co-infections including RSV determined below). Bocavirus was found in 2 cases diagnosed with VSD and DORV, and influenza B was found in 1 case diagnosed with VSD. In 3 other cases, viral co-infections found were influenza $A$ and Rinovirus in 1 case diagnosed with TOF; RSV and Parainfluenza virus in 1 case diagnosed with PDA and RSV; Parainfluenza, Rhinovirus and Human Metapneumonia virus in 1 other case diagnosed with VSD. RSV was not seen in the cyanotic group $(p=0.305)$. Three of 5 RSV infected patients (60\%) were hospitalized in winter. Therefore, these patients received incomplete RSV prophylaxis. Similarly, 5 of the total 9 viral agent $(+)$ patients $(55.6 \%)$ were hospitalized in winter (Table II). All of the RSV infected patients were under 12 months of age. Two of them had extracardiac risk factor (Down syndrome and prematurity with bronchopulmonary dysplasia). One (8.3\%) of the cyanotic patients who was a two-year-old boy with tracheostomy cannula and home ventilator had bacterial LRTI. The agent was Haemophilus influenzae. Four (10.5\%) of the acyanotic patients had also had bacterial LRTI. These were respectively 2,7,2 and 54 months old, and the agents were Stenotrophomonas maltophilia, Klebsiella pneumoniae, Pseudomonas aeruginosa. The second and fourth patients had neurological sequelae and cerebral palsy. Unfortunately, the first patient have been lost died in the pediatric intensive care unit (PICU) after surgery of severe $A C$ with respiratory system complications. One of the cyanotic patients who was aged 3 months, diagnosed with DORV and admitted to the PICU died due to respiratory failure. He had had no extracardiac problems and no viral or bacterial agents were detected. Thirteen of $38(34.2 \%)$ acyanotic patients needed PICU admission $(p=0.076)$, 2 of them died because of acute Respiratory Distress syndrome aged 2 months and 2 years, and they had had no extracardiac problems either.

\begin{tabular}{|l|l|l|l|}
\hline \multicolumn{4}{|l|}{ Table II. Viral agent frequency related season } \\
\hline Viral agent & Frequency (n) & $\%$ \\
\hline \multirow{4}{*}{$(+)$} & Winter & 5 & 55.6 \\
\cline { 2 - 4 } & Summer & 1 & 11.1 \\
\cline { 2 - 4 } & Spring & 3 & 33.3 \\
\cline { 2 - 4 } & Autumn & 0 & 0 \\
\cline { 2 - 4 } & Total & 9 & 100.0 \\
\hline (-) & Winter & 12 & 29.3 \\
\cline { 2 - 4 } & Summer & 7 & 17.1 \\
\cline { 2 - 4 } & Spring & 11 & 26.8 \\
\cline { 2 - 4 } & Autumn & 11 & 26.8 \\
\cline { 2 - 4 } & Total & 41 & 100.0 \\
\hline
\end{tabular}

The first patient had a bacterial agent, Stenotrophomonas maltophilia. Viral and bacterial agents were not found in the second patient. There was no statistically significant difference between the two groups (Table I). When compared for hospitalization times, there was no significant difference between the type of CHD, season, age and viral agent (Table III).

\section{Discussion}

LRTI are defined in the International Classification of Diseases as infections that affect airways below the epiglottis (5). Some children have predisposing risk factors such as prematurity, CHD, chronic lung disease, immune disorders, being below 5 years of age, enviromental smoke exposure, oropharyngeal incoordination with Aspiration syndrome (6-9). Also children with HS-CHD with congestive heart failure are more at risk for LRTI causing mortality and morbidity (10-12). Incidence of CHD differs for populations and the most common type of CHD is VSD (1). Some kind of CHD which leads to increased pulmonary flow (e.g. VSD, PDA) or $\mathrm{CHD}$ with desaturation (e.g. TOF, DORV, truncus arteriosus) carries a higher risk of recurrent respiratory tract infections and increased frequency of hospitalizations (2). According

\begin{tabular}{|c|c|c|}
\hline & $\begin{array}{l}\text { Hospitalization time (day) } \\
\text { Mean } \pm \text { standart deviation } \\
\text { Median (minimum-maximum) }\end{array}$ & $p$ value \\
\hline \multicolumn{2}{|l|}{ CHD } & \multirow{3}{*}{0.239} \\
\hline Cyanotic & $\begin{array}{l}12.68 \pm 11.909 \\
9.0(4-53)\end{array}$ & \\
\hline Acyanotic & $\begin{array}{l}13.53 \pm 7.357 \\
12.0(3-30)\end{array}$ & \\
\hline \multicolumn{2}{|l|}{ Season } & \multirow{5}{*}{0.578} \\
\hline Winter & $\begin{array}{l}12.35 \pm 8.046 \\
10.0(3-30)\end{array}$ & \\
\hline Summer & $\begin{array}{l}15.5 \pm 8.602 \\
15.5(5-26)\end{array}$ & \\
\hline Spring & $\begin{array}{l}10.78 \pm 4.838 \\
10.0(4-21)\end{array}$ & \\
\hline Autumn & $\begin{array}{l}16.18 \pm 13.526 \\
15.0(4-53)\end{array}$ & \\
\hline \multicolumn{2}{|l|}{ Age } & \multirow{3}{*}{0.114} \\
\hline$<12$ months & $\begin{array}{l}14.69 \pm 10.048 \\
13.0(3-53)\end{array}$ & \\
\hline$\geq 12$ months & $\begin{array}{l}10.47 \pm 5.535 \\
9.0(4-23)\end{array}$ & \\
\hline \multicolumn{2}{|c|}{ Respiratory viral panel } & \multirow{3}{*}{0.119} \\
\hline Agent + & $\begin{array}{l}9.44 \pm 5.228 \\
9.0(3-20)\end{array}$ & \\
\hline Agent - & $\begin{array}{l}14.09 \pm 9,412 \\
12.0(4-53)\end{array}$ & \\
\hline
\end{tabular}

CHD: Congenital heart disease 
to a review of 38 studies, especially HS-CHD patients with pulmonary congestion before the age of 2 are more likely to be hospitalized with severe RSV infections (13). In our study, similar to the literature, acyanotic CHD, especially VSD was the most frequent patient group that needed hospitalization for LRTI. We saw that children with pulmonary congestion were more at risk for PICU admission. Acute respiratory tract infections of childhood are usually seen before the age of 2. The American Academy of Pediatrics has included children with HS cyanotic CHD and acyanotic CHD, bronchopulmonary dysplasia, and prematurity in the high risk group for RSV infection, extended the age limit to 2 years, and recommended RSV prophylaxis (14). According to one study from China with 2721 hospitalized children those who were under 6 months old and who had CHD carried a higher risk of severe RSV disease (15). In our study $68 \%$ of the patients were younger than 12 months, $84 \%$ were younger than 24 months of age, similar to the literature (16-17). Medrano et al. (3) carried out CIVIC Epidemiologic Study with children who had HS-CHD, and found significant associated risk factors such as previous respiratory disease, incomplete immunoprophylaxis against RSV, Di George syndrome, Down syndrome, cardiopulmonary bypass, and siblings aged less than 11 years old. In the study, the most commonly identified infectious agent was RSV, like in our study. Also one study from Turkey by Ozyurt et al. (18) revealed that children having CHD without RSV prophylaxis are more at risk for complicated LRTI, LRTI-related hospitalization, and intensive care unit admission. They also stated that patients with prophylaxis in the presence of siblings under the age of 12 and and with congestive heart failure suffer from LRTI-related hospitalizations (18). Down syndrome with or without CHD is a risk factor leading to mortality or hospitalization (4). Similarly, in our study some patients had extracardiac risk factors and 4 of these patients were in early postoperative period after cardiopulmonary bypass (7 patients with Down syndrome and 1 patient with Di George syndrome, 7 patients with prematurity, 1 patient with congenital adrenal hyperplasia, 16/50). Additionally, in our study all of the patients had at least 1 , and $68 \%$ of the patients had 2 or more school-aged siblings. As we think that school-aged children act as a carrier, living with school-aged siblings increases the risk of LRTI and also the morbidity of LRTIs. Passive smoking or enviromental smoke exposure is also a risk factor causing recurrent LRTI $(19,20)$. But in contrast to the literature, in our study more than half of the patients had not been exposed to cigarette smoke. Hospitalization most commonly was seen in winter (34\% of all hospitalizations) but there was no significant difference regarding the hospitalization time of the patients in our study (Table II).

\section{Study Limitations}

The most important limitation was the number of patients in the study.

\section{Conclusion}

In this study we report children with $\mathrm{CHD}$, hospitalized in a single center having been diagnosed with LRTI; the demografic variables, risk factors, infectious agents causing mortality and morbidity in the light of the literature. To prevent these risk factors more studies must be done.

\section{Ethics}

Ethics Committee Approval: This study was approved by the Ege University Faculty of Medicine Ethics Commitee (approval number: 14-11/11).

Informed Consent: After being informed of the purpose and content of the study by the doctor and having read the information for patients, all the parents gave written informed consent.

Peer-review: External and internal peer-reviewed.

\section{Authorship Contributions}

Surgical and Medical Practices: E.K., Y.Ö.Ş., Z.Ü.T., Concept: Z.Ü.T., Design: Y.Ö.Ş., Z.Ü.T., Data Collection or Processing: E.K., Y.Ö.Ş., Analysis or Interpretation: E.K., Literature Search: Y.Ö.Ş., Writing: Y.Ö.Ş., Z.Ü.T.

Conflict of Interest: No conflict of interest was declared by the authors.

Financial Disclosure: The authors declared that this study received no financial support.

\section{References}

1. Hoffman JI, Kaplan S. The Incidence Of Congenital Heart Disease. J Am Coll Cardiol 2002;39;1890-900.

2. Pongiglione $G$, Possidoni $A$, di Luzio Paparatti, $U$ et al. Incidence of Respiratory Disease During the First Two Years of Life in Children with Hemodynamically Significant Congenital Heart Disease in Italy: A Retrospective Study. Pediatr Cardiol 2016;37:1581-9.

3. Medrano C, Garcia-Guereta L, Grueso J, et al. Respiratory infection in congenital cardiac disease. Hospitalizations in young children in Spain during 2004 and 2005: the CIVIC Epidemiologic Study. Cardiol Young 2007;17:360-71.

4. Kapoor S, Bhayana S, Singh A, Kishore J. Co-morbidities leading to mortality or hospitalization in children with Down syndrome and its effect on the quality of life of their parents. Indian J Pediatr 2014;81:1302-6.

5. Lanata CF, Rudan I, Boschi-Pinto C, et al. Methodological and quality issues in epidemiological studies of acute lower respiratory infections in children in developing countries. Int J Epidemiol 2004;33:1362-72.

6. Sommer C, Resch B, Simões EA. Risk factors for severe respiratory syncytial virus lower respiratory tract infection. Open Microbiol J 2011;5:144-54.

7. Fauroux B, Simões EAF, Checchia PA, et al. The Burden and Long-term Respiratory Morbidity Associated with Respiratory Syncytial Virus Infection in Early Childhood. Infect Dis Ther 2017;6:173-97.

8. Koch A, Mølbak K, Homøe P, et al. Risk factors for acute respiratory tract infections in young Greenlandic children. Am J Epidemiol 2003;158:374-84. 
9. Owayed AF, Campbell DM, Wang EE. Underlying causes of recurrent pneumonia in children. Arch Pediatr Adolesc Med 2000;154:190-4.

10. Nguyen TK, Tran TH, Roberts CL, Fox GJ, Graham SM, Marais BJ. Risk factors for child pneumonia - focus on the Western Pacific Region. Paediatr Respir Rev 2017;21:95101.

11. Zhang Q, Guo Z, Bai Z, MacDonald NE. A 4 year prospective study to determine risk factors for severe community acquired pneumonia in children in southern China. Ped Pulmonol 2013;48:390-7.

12. Sadoh WE, Osarogiagbon WO. Underlying congenital heart disease in Nigerian children with pneumonia. Afr Health Sci 2013;13:607-12.

13. Checchia PA, Paes B, Bont $L$, et al. Defining the Risk and Associated Morbidity and Mortality of Severe Respiratory Syncytial Virus Infection Among Infants with Congenital Heart Disease. Infect Dis Ther 2017;6:37-56.

14. Committee on Infectious Diseases. From the American Academy of Pediatrics: Policy statements-Modified Recommendations for use of palivizumab for prevention of respiratory syncytial virus infections. Pediatrics 2009;124:1694-701.
15. Zhang $T$, Zhu $Q$, Zhang $X$, et al. Clinical characteristics and direct medical cost of respiratory syncytial virus infection in children hospitalized in Suzhou, China. Pediatr Infect Dis J 2014;33:337-41.

16. Friedman $D$, Fryzek $J$, Jiang $X$, Bloomfield $A$, Ambrose CS, Wong PC. Respiratory syncytial virus hospitalization risk in the second year of life by specific congenital heart disease diagnoses. PLoS One 2017;12:e0172512.

17. Vizcarra-Ugalde S, Rico-Hernández M, Monjarás-Ávila $C$, et al. Intensive Care Unit Admission and Death Rates of Infants Admitted With Respiratory Syncytial Virus Lower Respiratory Tract Infection in Mexico. Pediatr Infect Dis J 2016;35:1199-203.

18. Ozyurt A, Narin N, Baykan A, et al. Efficacy of palivizumab prophylaxis among infants with congenital heart disease: $A$ case control study. Pediatr Pulmonol 2015;50:1025-32.

19. Vanker A, Gie RP, Zar HJ. The Association Between Environmental Tobacco Smoke Exposure and Childhood Respiratory Disease: A Review. Expert Rev Respir Med 2017;11:661-73.

20. Miyahara R, Takahashi K, Anh NT, et al. Exposure to paternal tobacco smoking increased child hospitalization for lower respiratory infections but not for other diseases in Vietnam. Sci Rep 2017;7:45481. 